\title{
Contrasting Smoking Behaviors of Non-daily Smokers - A Study based on Clustering of Repeated Daily Measures of Nicotine Exposure
}

Vishal Midya ( $\square$ vishal.midya@mssm.edu )

Icahn School of Medicine at Mount Sinai https://orcid.org/0000-0002-6643-5176

Andréa L. Hobkirk

Penn State College of Medicine

Nicolle M. Krebs

Penn State College of Medicine

Sophia I. Allen

Penn State College of Medicine

Lisa Reinhart

Penn State College of Medicine

Dongxiao Sun

Penn State College of Medicine

Andrea L. Stennett

Johns Hopkins University Bloomberg School of Public Health

Joshua E. Muscat

Penn State College of Medicine

Research article

Keywords: Non-daily smokers, Nicotine Exposure, Nicotine Dependence, Cluster Analysis, Smoking Behavior

Posted Date: November 9th, 2020

DOI: https://doi.org/10.21203/rs.3.rs-103011/v1

License: (c) (i) This work is licensed under a Creative Commons Attribution 4.0 International License.

Read Full License 


\section{Abstract}

Background: Over one-quarter of all smokers in the U.S. identify as non-daily smokers and this number is projected to rise. Despite the negative health effects of non-daily smoking and high rates of unsuccessful quit attempts, we know little about the variability and correlates of nicotine exposure among non-daily smokers.

Methods: A community sample of non-daily smokers $(n=60)$ ages 21 to 60 completed baseline measures of nicotine dependence, a consecutive 7-day at-home protocol to log each smoking session, ecological momentary assessments of mood and activity during smoking, and daily saliva samples for cotinine and nicotine metabolite ratio analysis. Hierarchical cluster analysis categorized participants based on their mean cotinine levels across days. Clusters were compared on biological and behavioral smoking characteristics, nicotine dependence, and activities and emotions during smoking using linear mixed effect regression models.

Results: Cluster analysis of cotinine revealed four distinct clusters of nicotine exposure, ranging from high levels (above $200 \mathrm{ng} / \mathrm{ml}$ ) to very low levels (near $0 \mathrm{ng} / \mathrm{ml}$ ). Compared to the other clusters, the cluster with the highest mean levels of cotinine also had the largest day-to-day variation in cotinine and was associated with significantly higher levels of nicotine dependence on the Fagerström Test of Nicotine Dependence and the Penn State Cigarette Dependence Index, lower rates of social smoking, and the highest frequency of negative emotions during smoking.

Conclusions: Our findings highlight the variability in nicotine exposure across days among non-daily smokers and show that some are exposed to levels near those of daily smokers. The results point to individual differences and existence of several sub-groups of nondaily smokers based on their nicotine exposure, which varied considerably across days for some, but not all groups. The results highlight the need to better characterize non-daily smokers and the factors that maintain smoking behavior to inform personalized cessation treatments for this growing population of smokers.

\section{Introduction}

The prevalence of cigarette smoking decreased from 21\% in 2005 to 14\% in 2017 [1]. However, the number of non-daily smokers is expected to rise as tobacco use becomes more expensive and restricted in the U.S $[2,3]$. Approximately one-quarter to one-third of all smokers in the U.S. identify as non-daily smokers who do not smoke a cigarette every day $[2,4]$. While non-daily smoking is linked to less health risks than daily smoking, non-daily smokers still have substantially higher rates of lung cancer and cardiovascular disease than the general population [5]. National trends suggest that low frequency smokers are becoming more nicotine dependent than in the past, possibly because this group is comprised of former heavy smokers [6]. Non-daily smokers are two times more likely to make a quit attempt than daily smokers, but their success rates (18-27\%) are not considerably higher than the $13 \%$ success rate found for daily smokers $[7,8]$. 
Despite the growing prevalence and associated health risks, nicotine exposure from non-daily smoking remains understudied. Mean urinary cotinine, the immediate metabolite of nicotine, is nearly three times lower among non-daily compared to daily smokers, while cotinine per cigarette is twice as high [9]. This difference does not appear to be driven by differential rates of nicotine metabolism, which has been shown to be similar among daily and non-daily smokers [9]. Non-daily smokers by definition do not engage in consistent levels of smoking, making it important to study nicotine exposure in a more proximal, granular context than only mean values. They report a wide range in the number of cigarettes they smoke per day and the number of days of abstinence between smoking days, making non-daily smokers a heterogeneous group that may have high variability in their day-to-day nicotine exposure [10, 11]. In other words, the cotinine value on one day may be considerably different than the value on another day. Thus, it is important to capture cotinine levels across several days to obtain an accurate picture of nicotine exposure for non-daily smokers.

Higher nicotine exposure among daily smokers is linked with higher nicotine dependence, specific smoking contexts and behaviors, and sociodemographic characteristics such as income [12-14]. It is unknown if these factors are associated with nicotine exposure among non-daily smokers as well. Overall, non-daily smokers have lower levels of nicotine dependence than daily smokers [8]. This has been replicated across different facets of dependence, including behavioral measures of dependence, smoking motives, and self-perceived loss of autonomy over smoking $[8,10]$. Smoking for non-daily smokers may be even more dependent on environmental and internal stimuli such as mood, activity, and social setting than for daily smokers [15]. A prior study using ecological momentary assessments among non-daily smokers found that smoking was most likely to occur during positive moods and leisure activities compared to negative and neutral mood states or performative and social activities [16].

For the current study, we first aimed to delineate subgroups of non-daily smokers based on their average cotinine levels using cluster analysis. Once defined, we examined associations of these clusters with 1) biological and behavioral smoking characteristics, 2) three measures of nicotine dependence, and 3) activities and emotions during smoking. Understanding the correlates of daily cotinine variation among non-daily smokers can provide insight into what factors might influence smoking behavior and nicotine exposure among this growing population of smokers.

\section{Methods}

\section{Participant Recruitment}

Non-daily smokers $(n=60)$ in Pennsylvania were recruited as a sub-sample of the Pennsylvania Adult Smoking Study (PASS) [17]. The PASS study investigated whether socioeconomic status predicts smoke exposure in daily smokers [18], and the current sub-study was designed to observe factors related to smoking for non-daily smokers specifically. Online advertisements, flyers, and peer-referrals were used for recruitment from 2014-2015. Participants were eligible if they reported smoking 4-24 days out of the past 30, and had this pattern for at least 6 months. Interested individuals were excluded if they reported 
that $>50 \%$ of their tobacco use was a product other than a cigarette, were currently pregnant, or engaged in active cessation attempts.

\section{Procedures}

If eligible after phone screening, participants were invited to an initial in-person visit where they provided written informed consent and completed a battery of questionnaires that included measures of nicotine dependence. During a 7-day at-home protocol, participants completed daily smoking logs, measures of smoking topography, ecological momentary assessments (EMA) during each smoking session (described below), and collected one saliva sample at approximately the same time each day for nicotine metabolite analysis. Participants returned all logs, topography equipment, and saliva samples at a final visit following the 7-day collection period. Topography data is not presented in this manuscript and a thorough description of the emotions and activities reported using EMA during each cigarette session has been published [16]. REDCap (Research Electronic Data Capture) tools hosted at the Penn State Milton S. Hershey Medical Center and College of Medicine were used for all data collection and management [19]. All study procedures were approved by the Institutional Review Board at the Penn State College of Medicine (037860EP).

\section{Salivary Cotinine}

Participants provided daily saliva samples for nicotine metabolite analysis. Cotinine has a longer half-life compared to nicotine, approximately 16 hours for cotinine versus 2 hours for nicotine, making it a sensitive measure of smoking even among light and non-daily smokers [20,21]. For daily saliva collection, participants placed a SalivaBio Oral Swab (Salimetrics, State College, Pennsylvania) under their tongues for 2 minutes. Participants stored the swabs in their home freezer until the final data collection visit. Swabs were kept frozen $\left(-80^{\circ} \mathrm{C}\right)$ in the laboratory until High Sensitivity Salivary Cotinine Quantitative Enzyme Immunoassay (ELISA; Salimetrics, State College, Pennsylvania) was carried out as directed by the manufacturer for the total sample. For 17 participants, immunoassay results were compared to assays conducted using mass spectrometry methods previously described [22] and modified for increased dilution in saliva samples using Triple TOF 5600 (AB SCIEX, Concord, Ontario, Canada). The same mass spectrometry methods were used to calculate cotinine and trans-3'hydroxycotinine $(3 \mathrm{HC})$ on each participant's initial saliva sample to determine nicotine metabolite ratio (NMR), calculated as $3 \mathrm{HC}$ divided by cotinine. Continuous NMR values were log transformed for analysis. Similar to previous studies, participants in the lowest quartile of NMR values $(\leq 0.31)$ were categorized as slow metabolizers and those in the top three quartiles as normal metabolizers [23]. To determine the reliability of cotinine over the course of a single day for non-daily smokers, six participants provided 4 extra saliva samples (5 total) three to four hours apart on one day. These were analyzed using immunoassay.

\section{Assessments}

Participants provided basic demographic information and detailed smoking histories. Those who answered "yes" to the question "Have you ever smoked daily for 6 months or longer?" were categorized 
as a "converted" non-daily smoker (i.e., converted to non-daily smoking from daily smoking) and those who answered no were categorized as a "native" non-daily smoker, as has been done in prior research [10].

Three measures of nicotine dependence were used to capture behavioral and psychological aspects of addiction. The Fagerström Test for Nicotine Dependence (FTND) measures behavioral aspects of dependence using six self-report questions (e.g., How many cigarettes a day do you smoke?) [24]. Scores of dependence range from 0 (low) to 10 (high) and internal consistency tends to be low given the independence of the items, which we found among the current sample (Cronbach's a $=0.38$ ). The Hooked on Nicotine Checklist (HONC) measures loss of perceived autonomy over smoking using 10 -items that assess past recall of withdrawal, craving, and quit attempts (e.g., Do you ever have strong cravings to smoke?) [25]. HONC scores range from 0 (low) to 10 (high) and internal consistency was good in the current sample as expected (Cronbach's a $=0.70$ ). The HONC is more sensitive to dependence among very light smokers, likely because the score is not weighted heavily by the number of cigarettes smoked per day like other dependence measures [26]. While the HONC was developed for a dichotomous scoring system with any item endorsement indicating loss of autonomy over smoking [27], we measured it as a continuous marker of the degree of autonomy as has been done previously with non-daily smokers [8, 26]. The Penn State Cigarette Dependence Index (PSCDI) [28] combines behavioral and psychological indicators of addiction through a combination of items from the FTND and HONC, two items assessing waking at night that were adapted from Bover et al. [29], and one item assessing the severity of urges to smoke adapted from Fidler et al. [30] Internal consistency for the PSCDI was low in the current sample (Cronbach's $a=0.42$ ). This is likely due to the mix of behavioral and psychological aspects of the measure that do not always correlate.

At each ad-lib smoking session, participants answered a series of questions about their current emotion, activity, time of day, urge, if they were alone, and if they were currently consuming alcohol. Activities were coded into four categories: leisure, performative, social, and interactive and emotions were categorized as: positive, negative, neutral, and mixed. The details of these categories, reliability of the coding procedure, and results of the EMA analysis are described in a prior publication [16]. Of note, social activities were defined as those that included leisure and social interaction (e.g., attending a party, time at a friend's house), while interaction activities were those that included dialogue and were not specifically leisure (e.g., business calls, arguments).

\section{Data Analysis}

Patterns of daily cotinine. Data were analyzed using R statistical software (version 3.6.1 (2019-07-05)). To categorize participants into groups based on similar levels of daily cotinine over the 7-day collection period, we used hierarchical clustering based on Ward's method [31]. To find the optimal number of clusters, we calculated a goodness of fit using the "gap statistics" in the "cluster" package in R [32] and sum of squares scree plots based on the "kmeans" algorithm (also called "Elbow" method) [33, 34]. To further reaffirm the clustering based on the cotinine values derived using ELISA, we conducted a second cluster analysis based on the cotinine values derived using mass-spectrometry for the sub-sample of 17 
participants. The number of clusters in the second model was kept the same as that of the first one (4 clusters) so that we could compare the exact grouping of those 17 participants between the two models. Cohen's Kappa and Bangdiwala's B were used to measure the agreement between the models [35]. The Fligner-Killeen test was used to test the null hypothesis that variance in cotinine values over the 7 days was the same for all clusters. Descriptive statistics were used to describe the sample in Table 1. Analysis of variance (ANOVA), chi-square tests, and post-hoc Tukey tests were used as appropriate to compare all demographic and smoking history variables across clusters in unadjusted models. These comparisons were used to identify covariates for further detailed analyses.

Associations of cotinine clusters with smoking characteristics, dependence, and activities and emotions. Separate, linear mixed effect regression models were used to examine the association of cluster group assignment with biological and behavioral smoking characteristics and measures of nicotine dependence after controlling for major demographic and smoking history covariates presented in Table 1. All mixed effect models included a random intercept for each participant and a random slope for clusters to take into account the underlying correlated structure and the following covariates: age, sex, race, total annual income, age at smoking initiation, and years of non-daily smoking. Parameter estimation was done based on Restricted Maximum Likelihood (REML) as implemented in R package "nlme". Post-hoc Wald tests were conducted to compare cluster specific estimated means to one another. False Discovery Rate (FDR) was implemented to correct for multiple comparison errors in p-values. Chi-square tests were used to compare the proportion of smoking activities and emotions collected via EMA by cluster. Twotailed p-values less than 0.05 were considered statistically significant.

\section{Results}

\section{Sample characteristics and tobacco use patterns}

Participant characteristics for each cluster are displayed in Table 1. The sample included 60 non-daily smokers ages 24 to 57 , who were primarily white (78\%) with an average total family income of $\$ 49,414$. Approximately half of the total sample was female (51.7\%) and married or living with a partner (45\%). On a self-report assessment, participants reported smoking a mean of $3.23(S D=1.83)$ cigarettes per day and $13.88(S D=5.25)$ days out of the past 30 . The sample began smoking regularly at a mean age of $19.48(S D=5.27)$ years and reported a mean of $8.07(S D=7.36)$ years of non-daily smoking. Sixty percent of the sample reported that they converted from daily smoking to non-daily smoking. The converted non-daily smokers reported switching from daily smoking $6.76(S D=7.07)$ years ago on average and previously smoking daily for a mean of $8.83(S D=7.36)$ years. 
Table 1

Demographic, baseline smoking, and 7-day smoking log variables by cluster
Cluster 1
Cluster
Cluster 3
$(n=8)$
$2 \quad(n=22)$
$(n=7)$
Cluster 4
$(n=23)$
Total
Sample ( $n$
$=60$ )
p-value of unadjusted analysis

Demographics

$\begin{array}{lllllll}\text { Age, mean (SD) } & 35.88 & 42.29 & 36.32 & 31.22 & 35.00 & 0.026 \\ & (8.71) & (5.85) & (10.62) & (7.05) \\ & & & & \text { \#[n } & (9.15) & \\ & & & \end{array}$

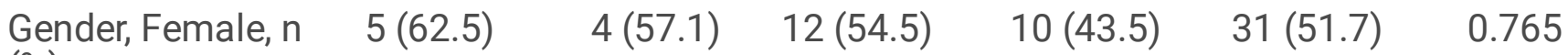
(\%)

Race, $\mathrm{n}(\%)$

0.228

White

$4(50.0)$

$6(85.7) \quad 20(90.9)$

$17(73.9)$

$47(78.3)$

Black/African

$3(37.5)$

$1(14.3) \quad 2(9.1)$

2 (8.7)

8 (13.3)

American

Asian

$1(12.5)$

$0(0.0) \quad 0(0.0)$

2 (8.7)

$3(5.0)$

Other

$0(0.0)$

$0(0.0) \quad 0(0.0)$

2 (8.7)

2 (3.3)

Latinx

$0(0.0)$

$1(14.3) \quad 1(4.5)$

4 (17.4)

$6(10.0)$

0.368

Marital status

Married/ live-in

partner

Divorced

$1(12.5)$

$2(28.6) \quad 2(9.1)$

$1(4.3)$

$6(10.0)$

Never married

$4(50.0)$

$3(42.9) \quad 8(36.4)$

12 (52.2)

27 (45.0)

Highest degree

$2(25.0)$

1 (14.3)

$5(22.7)$

3 (13.0)

11 (18.3)

0.795

HS/GED

Income

$\begin{array}{lll}20625 & 36429 & 67177 \\ (13928) & (16451) & (47079) \# \\ & & {[n=21]}\end{array}$

\section{1}

(33278)

49414

.016

0.823

$(38557){ }^{\#}$
$[n=59]$

Smoking Characteristics

\begin{tabular}{lllllll} 
Years non-daily & 6.90 & 5.14 & 10.09 & 7.43 & 8.07 & 0.387 \\
smoking & $(7.50)$ & $(4.81)$ & $(9.05)$ & $(6.19)$ & $(7.44)$ & \\
Age of initiation & 17.38 & 26.14 & 18.91 & $\begin{array}{l}18.74 \\
(3.76)\end{array}$ & $\begin{array}{l}19.48 \\
(5.27)\end{array}$ & 0.003 \\
& $(1.77)$ & $(9.51)$ & $(4.35)$ & $(5)$ & \\
\hline Converted non- & $5(62.5)$ & $5(71.4)$ & $14(63.6)$ & $12(52.2)$ & $36(60.0)$ & 0.775
\end{tabular}
daily 


\begin{tabular}{|c|c|c|c|c|c|c|}
\hline & $\begin{array}{l}\text { Cluster } 1 \\
(n=8)\end{array}$ & $\begin{array}{l}\text { Cluster } \\
2 \\
(n=7)\end{array}$ & $\begin{array}{l}\text { Cluster } 3 \\
(n=22)\end{array}$ & $\begin{array}{l}\text { Cluster } 4 \\
(n=23)\end{array}$ & $\begin{array}{l}\text { Total } \\
\text { Sample }(\mathrm{n} \\
=60)\end{array}$ & $\begin{array}{l}\text { p-value of } \\
\text { unadjusted } \\
\text { analysis }\end{array}$ \\
\hline $\begin{array}{l}\text { Years of daily } \\
\text { smoking }\end{array}$ & $\begin{array}{l}15.75 \\
(13.33) \# \\
{[n=4]}\end{array}$ & $\begin{array}{l}10.60 \\
(7.13)\end{array}$ & $\begin{array}{l}8.93 \\
(5.95)\end{array}$ & $\begin{array}{l}5.67 \\
(5.37)\end{array}$ & $\begin{array}{l}8.83 \\
(7.36) \#[n \\
=35]\end{array}$ & 0.104 \\
\hline $\begin{array}{l}\text { Years since daily } \\
\text { switching }\end{array}$ & $\begin{array}{l}8.67 \\
(7.10){ }^{\#[n} \\
=3]\end{array}$ & $\begin{array}{l}2.20 \\
(1.30)\end{array}$ & $\begin{array}{l}8.86 \\
(9.59)\end{array}$ & $\begin{array}{l}5.75 \\
(3.77)\end{array}$ & $\begin{array}{l}6.76 \\
(7.07) \#[n \\
=34]\end{array}$ & 0.295 \\
\hline $\begin{array}{l}\text { Days smoked in } \\
\text { past } 30\end{array}$ & $\begin{array}{l}17.25 \\
(4.77)\end{array}$ & $\begin{array}{l}14.43 \\
(6.29)\end{array}$ & $\begin{array}{l}15.64 \\
(4.19)\end{array}$ & $\begin{array}{l}10.85 \\
(4.70)\end{array}$ & $\begin{array}{l}13.88 \\
(5.25)\end{array}$ & 0.002 \\
\hline $\begin{array}{l}\text { Cigarettes per } \\
\text { day (past } 30 \\
\text { days) }\end{array}$ & $\begin{array}{l}3.50 \\
(0.93)\end{array}$ & $\begin{array}{l}3.29 \\
(0.95)\end{array}$ & $\begin{array}{l}3.34 \\
(2.25)\end{array}$ & $\begin{array}{l}3.02 \\
(1.86)\end{array}$ & $\begin{array}{l}3.23 \\
(1.82)\end{array}$ & 0.910 \\
\hline $\begin{array}{l}\text { Cigarettes per } \\
\text { day range }\end{array}$ & $2-5$ & $2-5$ & $1-11$ & $1-8$ & $1-11$ & \\
\hline $\begin{array}{l}\text { Time to first } \\
\text { cigarette }>60 \mathrm{~min}\end{array}$ & $3(37.5)$ & $7(100)$ & $21(95.5)$ & 21 (91.3) & $52(86.7)$ & 0.008 \\
\hline Tried quitting & $\begin{array}{l}6(85.7) \\
{[n=7]}\end{array}$ & $5(71.4)$ & $14(63.6)$ & $12(52.2)$ & $37(62.7)$ & 0.405 \\
\hline $\begin{array}{l}\text { Menthol } \\
\text { preference }\end{array}$ & $8(100)$ & $4(57.1)$ & $8(36.4)$ & $\begin{array}{l}12(54.5) \\
\#[n=22]\end{array}$ & $\begin{array}{l}32(54.2) \# \\
{[n=59]}\end{array}$ & 0.022 \\
\hline \multicolumn{7}{|c|}{ Nicotine Dependence } \\
\hline FTND & $\begin{array}{l}2.13 \\
(1.96)\end{array}$ & $\begin{array}{l}0.43 \\
(0.79)\end{array}$ & $\begin{array}{l}0.36 \\
(0.73)\end{array}$ & $\begin{array}{l}0.39 \\
(0.72)\end{array}$ & $\begin{array}{l}0.62 \\
(1.12)\end{array}$ & 0.001 \\
\hline PSCDI & $\begin{array}{l}5.75 \\
(3.15)\end{array}$ & $\begin{array}{l}3.14 \\
(1.68)\end{array}$ & $\begin{array}{l}2.82 \\
(1.47)\end{array}$ & $\begin{array}{l}2.17 \\
(1.83)\end{array}$ & $\begin{array}{l}3.00 \\
(2.19)\end{array}$ & 0.001 \\
\hline HONC & $\begin{array}{l}5.00 \\
(2.94) \#[\mathrm{n} \\
=7]\end{array}$ & $\begin{array}{l}4.14 \\
(2.41)\end{array}$ & $\begin{array}{l}4.27 \\
(1.98)\end{array}$ & $\begin{array}{l}3.57 \\
(1.81)\end{array}$ & $\begin{array}{l}4.07 \\
(2.09) \#[n \\
=59]\end{array}$ & 0.410 \\
\hline $\begin{array}{l}\text { Average smoking } \\
\text { days out of } 7\end{array}$ & $\begin{array}{l}4.75 \\
(1.91)\end{array}$ & $\begin{array}{l}4.57 \\
(1.99)\end{array}$ & $\begin{array}{l}4.23 \\
(1.74)\end{array}$ & $\begin{array}{l}2.83 \\
(1.50)\end{array}$ & $\begin{array}{l}3.80 \\
(1.84)\end{array}$ & 0.009 \\
\hline $\begin{array}{l}\text { Average CPD on } \\
\text { smoking days }\end{array}$ & $\begin{array}{l}2.35 \\
(1.07)\end{array}$ & $\begin{array}{l}2.53 \\
(1.02)\end{array}$ & $\begin{array}{l}3.02 \\
(1.66)\end{array}$ & $\begin{array}{l}1.68 \\
(1.09) \#[n \\
=22]\end{array}$ & $\begin{array}{l}2.37 \\
(1.42) \#[\mathrm{n} \\
=59]\end{array}$ & 0.016 \\
\hline $\begin{array}{l}\text { Average cotinine } \\
\text { per cigarette } \\
\text { (ng/ml/cig) }\end{array}$ & $\begin{array}{l}284.97 \\
(149.77)\end{array}$ & $\begin{array}{l}118.69 \\
(52.46)\end{array}$ & $\begin{array}{l}36.39 \\
(23.75)\end{array}$ & $\begin{array}{l}6.63 \\
(6.69) \#[n \\
=22]\end{array}$ & $\begin{array}{l}68.77 \\
(108.74) \# \\
{[n=59]}\end{array}$ & 0.001 \\
\hline
\end{tabular}




\begin{tabular}{|c|c|c|c|c|c|c|}
\hline & $\begin{array}{l}\text { Cluster } 1 \\
(n=8)\end{array}$ & $\begin{array}{l}\text { Cluster } \\
2 \\
(n=7)\end{array}$ & $\begin{array}{l}\text { Cluster } 3 \\
(n=22)\end{array}$ & $\begin{array}{l}\text { Cluster } 4 \\
(n=23)\end{array}$ & $\begin{array}{l}\text { Total } \\
\text { Sample }(\mathrm{n} \\
=60)\end{array}$ & $\begin{array}{l}\text { p-value of } \\
\text { unadjusted } \\
\text { analysis }\end{array}$ \\
\hline NMR ratio & $\begin{array}{l}0.44 \\
(0.23)\end{array}$ & $\begin{array}{l}0.69 \\
(0.32)\end{array}$ & $\begin{array}{l}0.55 \\
(0.22)\end{array}$ & $\begin{array}{l}0.55 \\
(0.49)\end{array}$ & $\begin{array}{l}0.55 \\
(0.36)\end{array}$ & 0.301 \\
\hline $\begin{array}{l}\text { Slow } \\
\text { metabolizers }\end{array}$ & $3(37.5)$ & $0(0.0)$ & $2(9.1)$ & $10(43.5)$ & $15(25.0)$ & 0.017 \\
\hline \multicolumn{7}{|c|}{$\begin{array}{l}\text { Note: P-values based on unadjusted analyses of variance and chi-square tests. }{ }^{\text {Mean, standard }} \\
\text { deviation, and unadjusted group analysis based on reduced cluster sample size due to missing } \\
\text { values. NMR = nicotine metabolite ratio; FTND = Fagerström Test for Nicotine Dependence; PSUCDI = } \\
\text { Penn State University Cigarette Dependence Index; HONC = Hooked on Nicotine Checklist; CPD = } \\
\text { cigarettes per day. }\end{array}$} \\
\hline
\end{tabular}

\section{Cluster analysis of cotinine patterns}

Both gap statistics and Elbow method revealed four distinct clusters of average cotinine levels. Individual participant cotinine values across 7 days are displayed by cluster in Fig. 1. Cotinine was collected in 51 saliva samples for 8 participants in cluster 1, 46 saliva samples for 7 participants in cluster 2, 153 saliva samples for 22 participants in cluster 3 , and 160 saliva samples in 23 participants in cluster 4 for a total of 410 samples overall. Clusters 1 through 4 are characterized by significantly descending values of mean cotinine across the seven days. Cotinine values $(\mathrm{ng} / \mathrm{ml})$ in each saliva sample ranged from 257.83 to 949.63 for cluster $1,14.84$ to 466.06 for cluster $2,1.68-247.69$ for cluster 3 , and 0.00 to 66.72 for cluster 4 . The linear mixed effect model confirmed a significant difference in mean cotinine between the cluster groups (Table 2). A chi-square test of the homogeneity of variance in daily cotinine values across clusters was also significant $\left(\chi^{2}(3)=31.50, p<0.001\right)$, suggesting that the day-to-day variation in cotinine was significantly different by cluster. Post-hoc tests revealed that cluster 1 had significantly more day-today variance than clusters 3 and 4 and cluster 2 had significantly more day-to-day variance than cluster 4 (all $p<0.05$ ).

Figure 2 displays the results of the confirmatory cluster analysis of daily cotinine analyzed using mass spectrometry. There was fair agreement between the two cluster models conducted on the cotinine values derived using ELISA and mass spectrometry (weighted kappa $=0.68$; Bangdiwala's $B=0.72$ ). This agreement was indicative of a relatively good fit for four clusters of varying daily cotinine patterns in both models. In the confirmatory model, participants in Cluster 1 from the original model were separated into three clusters $(1,2$, and 3$)$ and participants from Clusters 3 and 4 from the original model were categorized into one cluster (4). Such categorization might have happened due to small sample size ( $\mathrm{n}=$ 17) for the confirmatory model.

\section{Demographic characteristics by cluster (Unadjusted analysis)}


Results of descriptive statistics and the unadjusted analyses are displayed in Table 1. There were significant cluster group differences in age and total annual family income. Cluster 2 was significantly older than cluster 4, and cluster 1 reported significantly less income than cluster 3 in post-hoc Tukey tests. There were no other significant cluster differences in demographic characteristics.

There were significant differences across clusters for the age of smoking initiation, days smoked in the past 30 days, average daily time to the first cigarette smoked, and menthol preference. Cluster 2 participants-initiated smoking around the age of 26 , which was significantly older than the other three clusters that initiated smoking on average in their late teens. Cluster 4 reported smoking significantly less days out of the past 30 than clusters 1 and 3 . Only $38 \%$ of cluster 1 participants reported waiting more than an hour to smoke their first cigarette which was significantly less than the other clusters with more than $90 \%$ of these groups waiting longer than an hour. Cluster 1 was comprised of $100 \%$ menthol smokers while cluster 3 was comprised of less than half menthol smokers (36.4\%). There were no significant differences in the proportion of participants who were native non-daily smokers vs. those who converted from daily smoking between the clusters. Five participants reported using a tobacco product other than a cigarette during the week; three participants reported one day of e-cig, snuff, or hookah use. One participant reported smoking a cigar on two days.

\section{Linear mixed effect models by cluster (Adjusted analysis)}

Biological and behavioral smoking characteristics. Results of the linear mixed effect models are included in Table 2 (only regression estimates of the Clusters were presented in the table). Over the 7-day collection period, 574 smoking sessions were recorded. Participants reported smoking an average of 3.80 days out of seven $(S D=1.84)$. There were significant cluster differences in smoking days with significantly more days of smoking in cluster 1 compared to cluster 4 . On the days that participants reported smoking, they smoked an average of 2.37 cigarettes per day $(S D=1.42)$. The total daily number ranged from 0 to $7 \mathrm{CPD}$. Cluster 3 smoked significantly more cigarettes per day than cluster 4 . The same results were found when this analysis was run with all tobacco product use instead of CPD. Cotinine per cigarette was significantly different for all clusters with cluster 1 being the highest, followed by cluster 2 , cluster 3 , and cluster 4 . There were no significant differences in the mean log transformed NMR or the proportion of slow vs. normal metabolizers across the clusters. Slow metabolizers made up $38 \%$ of cluster $1,0 \%$ of cluster $2,9 \%$ of cluster 3 , and $44 \%$ of cluster 4 .

Nicotine dependence. There were significant differences across clusters for the two behavioral measures of dependence, the FTND and PSCDI. The difference was driven by cluster 1 which had higher levels of dependence than all other clusters. Dependence scores for each cluster are displayed in bar graphs in Fig. 3. There were no significant differences in HONC scores between the clusters. However, HONC scores for non-daily smokers are complicated by items that do not specify when the behavior occurred (e.g., Have you everfelt like you were addicted to tobacco?). Smokers who converted from daily to non-daily smoking may endorse these items in reference to their past history of daily smoking, which could inflate HONC dependence scores. To provide more clarity, we conducted post-hoc tests to determine if converted vs. native smokers had higher HONC scores for each cluster separately. We found significantly higher 
mean HONC scores among converted $(M=4.93, S D=1.94)$ compared to non-converted $(M=3.12, S D=$ 1.55) smokers in Cluster $3(t=2.24, p=0.036)$ and converted $(M=4.31, S D=1.65)$ compared to nonconverted $(M=2.60, S D=1.58)$ smokers in Cluster $4(t=2.50, p=0.021)$, but not Clusters 1 and 2 . In an additional to post-hoc tests, we examined cluster differences in response to the HONC item, "Do you smoke now because it is really hard to quit?", which assesses perceptions of current loss of autonomy. We did not find a significant difference between the clusters for this item. 
Table 2

Results of the linear mixed effect regression models

\begin{tabular}{|c|c|c|c|c|}
\hline Model & & SE & $\mathrm{t}$-value & p-value \\
\hline \multicolumn{5}{|l|}{ Cotinine } \\
\hline Intercept & 6.73 & 0.46 & 14.74 & .001 \\
\hline Cluster 2 & -1.03 & 0.29 & -3.51 & .001 \\
\hline Cluster 3 & -2.36 & 0.23 & -10.42 & .001 \\
\hline Cluster 4 & -4.53 & 0.27 & -16.63 & .001 \\
\hline \multicolumn{5}{|c|}{ Cotinine/Cigarette } \\
\hline Intercept & 360.97 & 52.39 & 6.89 & .001 \\
\hline Cluster 2 & -207.91 & 38.96 & -5.34 & .001 \\
\hline Cluster 3 & -305.25 & 30.89 & -9.88 & .001 \\
\hline Cluster 4 & -339.99 & 30.09 & -11.30 & .001 \\
\hline \multicolumn{5}{|l|}{ CPD } \\
\hline Intercept & 2.01 & 1.39 & 1.44 & .156 \\
\hline Cluster 2 & 0.38 & 1.03 & 0.36 & .718 \\
\hline Cluster 3 & 0.67 & 0.82 & 0.82 & .416 \\
\hline Cluster 4 & -0.56 & 0.80 & -0.71 & .483 \\
\hline \multicolumn{5}{|l|}{ NMR (log) } \\
\hline Intercept & 0.25 & 0.18 & 1.35 & .184 \\
\hline Cluster 2 & 0.05 & 0.14 & 0.39 & .698 \\
\hline Cluster 3 & 0.06 & 0.11 & 0.55 & .582 \\
\hline Cluster 4 & 0.04 & 0.10 & 0.36 & .718 \\
\hline \multicolumn{5}{|c|}{ NMR cut-off } \\
\hline Intercept & 4.29 & 3.52 & 1.22 & .223 \\
\hline Cluster 2 & 15.92 & 401.65 & 0.04 & .968 \\
\hline Cluster 3 & 3.88 & 2.41 & 1.61 & .107 \\
\hline Cluster 4 & 0.64 & 1.38 & 0.46 & .643 \\
\hline
\end{tabular}




\begin{tabular}{|c|c|c|c|c|}
\hline Model & & SE & $\mathrm{t}$-value & p-value \\
\hline Intercept & 0.64 & 0.60 & 1.08 & .286 \\
\hline Cluster 2 & -0.01 & 0.40 & -0.02 & .986 \\
\hline Cluster 3 & -0.18 & 0.35 & -0.50 & .618 \\
\hline Cluster 4 & -0.28 & 0.32 & -0.87 & .387 \\
\hline \multicolumn{5}{|l|}{ PSUCDI } \\
\hline Intercept & 4.54 & 1.49 & 3.05 & .004 \\
\hline Cluster 2 & -0.56 & 1.11 & -0.50 & .619 \\
\hline Cluster 3 & -0.64 & 0.96 & -0.67 & .509 \\
\hline Cluster 4 & -1.36 & 0.92 & -1.48 & .146 \\
\hline \multicolumn{5}{|l|}{ HONC } \\
\hline Intercept & 5.11 & 1.75 & 2.92 & .006 \\
\hline Cluster 2 & 0.18 & 1.29 & 0.14 & .887 \\
\hline Cluster 3 & 0.63 & 1.14 & 0.55 & .582 \\
\hline Cluster 4 & 0.16 & 1.08 & 0.15 & .884 \\
\hline \multicolumn{5}{|c|}{ Hard to Quit } \\
\hline Intercept & 0.04 & 0.33 & 1.28 & .206 \\
\hline Cluster 2 & -0.03 & 0.25 & -1.27 & .209 \\
\hline Cluster 3 & -0.02 & 1.19 & -1.08 & .288 \\
\hline Cluster 4 & -1.70 & 0.19 & -1.08 & .376 \\
\hline \multicolumn{5}{|c|}{ Smoking days } \\
\hline Intercept & 4.39 & 1.59 & 2.76 & .008 \\
\hline Cluster 2 & -0.39 & 1.18 & -0.33 & .744 \\
\hline Cluster 3 & -1.12 & 0.93 & -1.20 & .236 \\
\hline Cluster 4 & -2.29 & 0.91 & -2.50 & .016 \\
\hline \multicolumn{5}{|c|}{$\begin{array}{l}\text { Note: } \mathrm{CPD}=\text { cigarettes per day (only on days at least one cigarette was smoked); NMR = nicotine } \\
\text { metabolite ratio; NMR cut-off includes slow metabolizers }(\leq 0.31) \text { and normal metabolizers }(>0.31 \\
\text { FTND = Fagerström Test for Nicotine Dependence; PSUCDI = Penn State University Cigarette } \\
\text { Dependence Index; HONC = Hooked on Nicotine Checklist }\end{array}$} \\
\hline
\end{tabular}

\section{Smoking activities and emotions by cluster}


Figure 4 displays the actions and emotions reported during smoking sessions across clusters. In total, the sample reported 561 smoking emotions and actions. Participants reported being alone for $58.92 \%$ and using alcohol for $23.48 \%$ of all reported experiences of tobacco use. All clusters reported leisure followed by performative activities most often during smoking. However, the clusters had significantly different proportions of smoking actions $\left[X^{2}(9)=33.05, p<0.001\right]$, with Cluster 1 reporting the least social smoking (3.13\%) and the most interaction smoking (16.67\%) of all the clusters. Alternatively, Cluster 3 reported the most social smoking $(23.62 \%)$ and the least interaction smoking $(2.76 \%)$ of all the clusters. There was a significant cluster difference in the proportion of emotions reported during smoking experiences $\left[X^{2}(9)=\right.$ 19.31, $p=0$.023]. This difference was primarily driven by Cluster 1's distribution of emotions whereby negative emotions were the most prevalent $(45.16 \%)$ followed by positive $(30.11 \%)$, neutral $(16.12 \%)$, and mixed $(8.60 \%)$. For all other clusters, positive emotions were most prevalent, followed by negative, neutral and mixed.

\section{Discussion}

The current study found four different subgroups of nicotine exposure over a 7-day collection period among a sample of non-daily smokers. The clusters ranged from relatively high mean levels of cotinine that were similar to those measured among daily smokers [36], to consistently low mean cotinine levels similar to non-smokers exposed only to environmental smoke [37]. As expected, cotinine levels increased with more smoking days in the week and more cigarettes smoked per day. There was considerable variation in cotinine between days for some clusters, which confirms that high variability in smoking behavior for non-daily smokers can lead to similar variability in nicotine exposure. Cotinine did, however, remain fairly stable within the day, especially for the smokers who maintained low cotinine levels across days.

Nicotine exposure varied with some demographic and smoking characteristics. The high cotinine nondaily smokers had the lowest income of all groups and was comprised of menthol smokers only. This is consistent with research among daily smokers showing that rates of smoking, nicotine exposure, and levels of dependence are all higher among low income smokers compared to higher income smokers [2, $14,18]$. Higher cotinine levels among low versus high income smokers may be related to more perceived stress, easier access to cigarettes, and a lack of enforcement of smoking regulations where individuals live and work [18, 38, 39]. Among daily smokers, menthol smoking is often a correlate of lower SES as it was in the current sample [14]. The U.S. Food and Drug Administration (FDA) concluded that the use of menthol cigarettes is more common among low income smokers and related to higher rates of dependence [40]. Although there are some reports that menthol is associated with higher nicotine intake, an FDA review did not confirm this finding [40]. Higher cotinine levels among the current sample are likely due to more cigarettes smoked per day, rather than menthol preference.

We found a dose-response relationship between daily cotinine levels and nicotine dependence. The subgroup with the highest levels of cotinine also had the highest average dependence scores and were more likely to report smoking their first cigarette $<60$ minutes after waking, which is a strong predictor of 
nicotine dependence [41]. Surprisingly, there was not a significant difference in the number of converted vs. native non-daily smokers between the clusters, which has been hypothesized to contribute to increasing dependence among light and non-daily smokers [6]. However, the results highlight that nicotine exposure is likely not the only factor determining dependence among non-daily smokers. Even the group with cotinine levels that were consistently above $200 \mathrm{ng} / \mathrm{ml}$ reported low levels of dependence and only $50 \%$ of this cluster reported that they smoke now because it's hard to quit. Further, the group with cotinine levels near $0 \mathrm{ng} / \mathrm{ml}$ still endorsed aspects of dependence with over $20 \%$ of this group reporting that they continue to smoke now because it is hard for them to quit.

Prior research has shown that non-daily smokers have stronger stimulus control over their smoking than daily smokers [15]. Stimulus control occurs when a smokers' mood, activity, and environmental context become important predictors of smoking behavior, rather than nicotine withdrawal alone [15]. This could explain why our subgroups with low levels of nicotine exposure still reported perceived symptoms of nicotine dependence. Our EMA results from the current study and a prior analysis of the sample found that smoking occurred most frequently during positive moods and activities of leisure [16]. Further, we found that the group with the lowest cotinine had more social smoking than the high cotinine cluster. Alternatively, participants with the highest levels of cotinine were more likely to report negative emotions during their smoking experiences and smoking during interactions such as phone calls and arguments. This is in part contrary to a laboratory study showing positive affect to be linked to higher nicotine boost among daily smokers [13]. This could have several explanations. Given the relatively higher levels of dependence among this group, these smokers may experience withdrawal symptoms that induce negative emotions, like irritability and anxiety, which precede and then accompany their next smoking experience. Another potential explanation is that the high cotinine group smokes to alleviate perceived stress. Experimentally induced stress has been shown to trigger negative affect and craving among heavy and light smokers and is commonly reported as a barrier to cessation [42, 43]. Future research exploring real-time smoking motives among non-daily smokers may help to elucidate why negative emotions are associated with higher cotinine levels for this group and how we might intervene on these emotions to reduce smoking behavior (see [44] for review).

The current study had several limitations. The sample, comprised primarily of non-Hispanic White smokers, was not nationally representative. For this reason our results may not generalize to Black and Hispanic smokers who are known to have higher rates of non-daily smoking than the general population [45]. In addition, our EMA relied on participants' initiative to record each smoking session and some participants may have under-reported the number of cigarettes smoked; however, the sample's selfreported CPD was consistent with prior studies of adults and adolescents [9]. Unexpectedly, the level of cotinine for cluster 1 was significantly higher than the other clusters while the average CPD was similar across cluster. This cluster was not comprised of slower nicotine metabolizers. Further research is needed to better understand the reasons for this discrepancy in cotinine values. Although it is possible that this group was underreporting their cigarettes per day, it would be unlikely for participants to also underreport their levels of dependence on items that are not face valid (e.g., time to first cigarette), suggesting that 
these were true non-daily smokers. Other factors could explain the high cotinine levels among this group, such as compensatory smoking.

In conclusion, the current study highlights that nicotine exposure among non-daily smokers is as variable as their self-reported patterns of smoking behavior. With a wide range in nicotine exposure and consistently low nicotine dependence and cessation rates, non-daily smokers may not fit with the longheld theory that nicotine is the primary factor that sustains smoking addiction [46]. Instead, these findings point to the need for more detailed assessments of smoking behavior to guide the development of effective cessation interventions for this group of smokers. Future research could inform our limited understanding of the biobehavioral mechanisms that contribute to individual differences in nicotine exposure among non-daily smokers and inform the development of personalized interventions that help non-daily smokers manage internal and external cues for smoking.

\section{Declarations}

\section{Ethics approval and consent to participate}

All study procedures were approved by the Institutional Review Board at the Penn State College of Medicine (037860EP).

\section{Consent for publication}

Not Applicable

\section{Availability of data and materials}

The minimal data underlying the results of this study are available upon request due to ethical and legal restrictions imposed by the Penn State University Institutional Review Board. Data cannot be shared publicly because the data collected is from human subjects who consented only to the research team having access to their data. The participants did not consent to having their data shared publicly. Data are available from the Penn State College of Medicine Institutional Data Access (contact via 717-5315687 or hspo@pennstatehealth.psu.edu).

\section{Competing interests}

The authors declare that they have no competing interests.

\section{Funding}


This research was supported by the National Institute on Drug Abuse grant numbers R01DA026815 (JM) \& K23DA045081 (ALH) and the National Center for Advancing Translational Sciences grant numbers UL1TR00127 \& UL1TR002014 of the National Institutes of Health. The funders had no role in study design, data collection and analysis, decision to publish, or preparation of the manuscript.

\section{Authors' contributions}

Vishal Midya: Formal Analysis, Visualization, Writing Original Draft and Review

Andrea Hobkirk: Writing Original Draft, Formal Analysis, Visualization and Review

Joshua Muscat: Conceptualization, Writing Original Draft and Review

Nicolle Krebs: Project Administration, Writing Original Draft and Review

Andrea Stennett: Project Administration, Writing Original Draft

Sophia Allen: Writing Draft and Review

Lisa Reinhart: Writing Draft and Review

Dongxiao Sun: Formal Analysis, Writing Draft and Review

\section{Acknowledgements}

The authors would like to thank the Mass Spectrometry Core Facility at Penn State University College of Medicine for their services.

\section{References}

1. Wang TW, Asman K, Gentzke AS, Cullen KA, Holder-Hayes E, Reyes-Guzman CM, et al. Tobacco Product Use Among Adults- United States, 2017. 2018.

2. Jamal A, Phillips E, Gentzke AS, Homa DM, Babb SD, King BA, et al. Current cigarette smoking among adults - United States, 2016. 2018.

3. Dinno A, Glantz S. Tobacco control policies are egalitarian: a vulnerabilities perspective on clean indoor air laws, cigarette prices, and tobacco use disparities. Soc Sci Med. 2009;68(8):1439-47.

4. Reyes-Guzman CM, Pfeiffer RM, Lubin J, Freedman ND, Cleary SD, Levine PH, et al. Determinants of Light and Intermittent Smoking in the United States: Results from Three Pooled National Health Surveys. Cancer Epidemiol Biomarkers Prev. 2017;26(2):228-39.

5. Schane RE, Ling PM, Glantz SA. Health effects of light and intermittent smoking: a review. Circulation. 2010;121(13):1518-22. 
6. Goodwin RD, Wall MM, Gbedemah M, Hu MC, Weinberger AH, Galea S, et al. Trends in cigarette consumption and time to first cigarette on awakening from 2002 to 2015 in the USA: new insights into the ongoing tobacco epidemic. Tob Control. 2018;27(4):379-84.

7. Tindle H, Shiffman S. Smoking cessation behavior among intermittent smokers versus daily smokers. American Journal of Public Health. 2011;101(7):e1-e3.

8. Shiffman S, Ferguson SG, Dunbar MS, Scholl SM. Tobacco dependence among intermittent smokers. Nicotine Tob Res. 2012;14(11):1372-81.

9. Shiffman S, Dunbar MS, Benowitz NL. A comparison of nicotine biomarkers and smoking patterns in daily and nondaily smokers. Cancer Epidemiol Biomarkers Prev. 2014;23(7):1264-72.

10. Shiffman S, Tindle H, Li X, Scholl S, Dunbar M, Mitchell-Miland C. Characteristics and smoking patterns of intermittent smokers. Exp Clin Psychopharmacol. 2012;20(4):264-77.

11. Shiffman S. Light and intermittent smokers: background and perspective. Nicotine Tob Res. 2009;11(2):122-5.

12. Perez-Stable EJ, Herrera B, Jacob P, Benowitz N. Nicotine metabolism and intake among black and white smokers. Journal of American Medical Association. 1998;280:152-6.

13. Patterson F, Benowitz N, Shields PG, Kaufmann V, Jepson C, Wileyto EP, et al. Individual differences in nicotine intake per cigarette. Cancer Epidemiology, Biomarkers \& Prevention. 2003;12:468-71.

14. Chen A, Machiorlatti M, Krebs NM, Muscat JE. Socioeconomic differences in nicotine exposure and dependence in adult daily smokers. BMC Public Health. 2019;19(1):375.

15. Shiffman S, Dunbar MS, Ferguson SG. Stimulus control in intermittent and daily smokers. Psychol Addict Behav. 2015;29(4):847-55.

16. Stennett A, Krebs NM, Liao J, Richie JP, Jr., Muscat JE. Ecological momentary assessment of smoking behaviors in native and converted intermittent smokers. Am J Addict. 2018;27(2):131-8.

17. Krebs NM, Chen A, Zhu J, Sun D, Liao J, Stennett AL, et al. Comparison of Puff Volume With Cigarettes per Day in Predicting Nicotine Uptake Among Daily Smokers. Am J Epidemiol. 2016;184(1):48-57.

18. Hobkirk AL, Krebs NM, Muscat JE. Income as a moderator of psychological stress and nicotine dependence among adult smokers. Addict Behav. 2018;84:215-23.

19. Harris PA, Taylor R, Thielke R, Payne J, Gonzalez N, Conde JG. Research electronic data capture (REDCap)-A metadata-driven methodology and workflow process for providing translational research informatics support. Journal of Biomedical Informatics. 2009;42(2):377-81.

20. Carey KB, Abrams DB. Properties of saliva cotinine in young adult light smokers. American Journal of Public Health. 1988;78(7):842-3.

21. Benowitz N, Jacob III P. Metabolism of nicotine to cotinne studied by a dual stable isotope method. Clinical Pharmacology \& Therapeutics. 1994;56(5):483-93.

22. Chen A, Krebs NM, Zhu J, Muscat JE. Nicotine metabolite ratio predicts smoking topography: The Pennsylvania Adult Smoking Study. Drug Alcohol Depend. 2018;190:89-93. 
23. Falcone M, Jepson C, Benowitz N, Bergen AW, Pinto A, Wileyto EP, et al. Association of the nicotine metabolite ratio and CHRNA5/CHRNA3 polymorphisms with smoking rate among treatment-seeking smokers. Nicotine Tob Res. 2011;13(6):498-503.

24. Heatherton TF, Kozlowski LT, Frecker RC, Fagerstrom K. The Fagerstrom Test for Nicotine Dependence: a revision of the Fagerstrom Tolerance Questionnaire. British Journal of Addiction. 1991;86:1119-27.

25. Wellman RJ, DiFranza JR, Savageau JA, Godiwala S, Friedman K, Hazelton J. Measuring adults' loss of autonomy over nicotine use: the Hooked on Nicotine Checklist. Nicotine Tob Res. 2005;7(1):15761.

26. Wellman RJ, Savageau JA, Godiwala S, Savageau N, Friedman K, Hazelton J, et al. A comparison of the Hooked on Nicotine Checklist and the Fagerstrom Test for Nicotine Dependence in adult smokers. Nicotine Tob Res. 2006;8(4):575-80.

27. DiFranza JR, Savageau JA, Fletcher K, Ockene JK, Rigotti NA, McNeill AD, et al. Measuring the loss of autonomy over nicotine use in adolescents. Arch Pediatr Adolesc Med. 2002;156:397-403.

28. Foulds J, Veldheer S, Yingst J, Hrabovsky S, Wilson SJ, Nichols TT, et al. Development of a questionnaire for assessing dependence on electronic cigarettes among a large sample of exsmoking E-cigarette users. Nicotine Tob Res. 2015;17(2):186-92.

29. Bover MT, Foulds J, Steinberg MB, Richardson D, Marcella SW. Waking at night to smoke as a marker for tobacco dependence: patient characteristics and relationship to treatment outcome. Int J Clin Pract. 2008;62(2):182-90.

30. Fidler JA, Shahab L, West R. Strength of urges to smoke as a measure of severity of cigarette dependence: comparison with the Fagerstrom Test for Nicotine Dependence and its components. Addiction. 2011;106(3):631-8.

31. Murtagh F, Legendre P. Ward's Hierarchical Agglomerative Clustering Method: Which algorithms implement Ward's criterion? . Journal of Classification. 2014;31:274-95.

32. Maechler M, Rousseeuw P, Struyf A, Hubert M, Hornik K. cluster: Cluster analysis basics and extensions. 2018.

33. Tibshirani R, Walther G, Hastie T. Estimating the number of clusters in a data set via the gap statistic. J R Statistic Soc B. 2001;63(Part 2):411-23.

34. Thorndike RL. Who belongs in the family? Psychometrika. 1953;18(4):267-76.

35. Munoz SR, Bandiwala SI. Interpretation of Kappy and B statistics measures of agreement. Journal of Applied Statistics. 2010;24(1):105-12.

36. Langone JJ, Cook G, Bjercke RJ, Lifschitz MH. Monoclonal antibody ELISA for cotinine in saliva and urine of active and passive smokers. Journal of Immunological Methods. 1988;114:73-8.

37. Jarvis MJ, Fidler J, Mindell J, Feyerabend C, West R. Assessing smoking status in children, adolescents and adults: cotinine cut-points revisited. Addiction. 2008;103(9):1553-61. 
38. Shavers VL, Fagan P, Jouridine Alexander LA, Clayton R, Doucet J, Baezconde-Garbanati L. Workplace and home smoking restrictions and racial/ethnic variation in the prevalence and intensity of current cigarette smoking among women by poverty status, TUS-CPS 1998-1999 and 2001-2002. Journal of Epidemiology \& Community Health. 2006;60(Supplement 2):ii34-ii43.

39. Laws MB, Whitman J, Bowser DM, Krech L. Tobacco availability and point of sale marketing in demographically constrasting districts of Massachusetts. Tobacco Control. 2002;11(Suppl II):ii71-ii3.

40. FDA. Preliminary scientific evaluation of the possible public health effects of menthol versus nonmenthol cigarettes. 2013.

41. Fagerström K. Time to first cigarette; the best single indicator of tobacco dependence? Monaldi Arch Chest Dis. 2003;59(1):91-4.

42. Carim-Todd L, Mitchell SH, Oken BS. Impulsivity and Stress Response in Nondependent Smokers (Tobacco Chippers) in Comparison to Heavy Smokers and Nonsmokers. Nicotine \& Tobacco Research. 2016;18(5):547-56.

43. Twyman L, Bonevski B, Paul C, Bryant J. Perceived barriers to smoking cessation in selected vulnerable groups: a systematic review of the qualitative and quantitative literature. BMJ Open. 2014;4(12):e006414.

44. Carmody TP, Vieten C, Astin JA. Negative affect, emotional acceptance, and smoking cessation. J Psychoactive Drugs. 2007;39(4):499-508.

45. Trinidad DR, Perez-Stable EJ, Emery SL, White MM, Grana RA, Messer KS. Intermittent and light daily smoking across racial/ethnic groups in the United States. Nicotine Tob Res. 2009;11(2):203-10.

46. Benowitz NL, Henningfield JE. Establishing a nicotine threshold for addiction: The implications for tobacco regulation. NEJM. 1994;331(2):123-5.

\section{Figures}




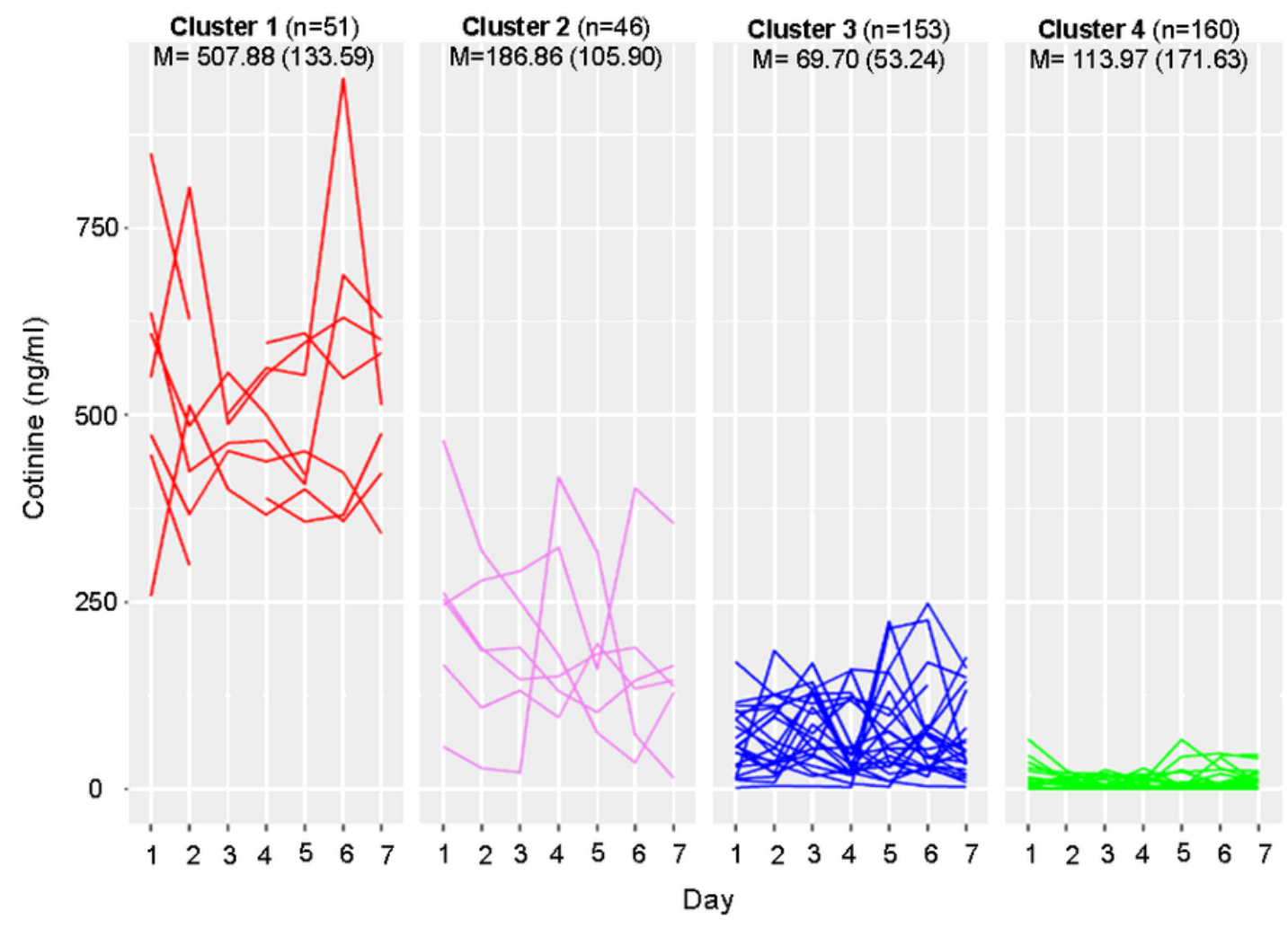

\section{Figure 1}

Results of the cluster analysis categorizing participants into groups based on similar mean levels of cotinine across 7 days of saliva collection. Cotinine was analyzed using ELISA. The sample size (n) in the figure is the number of saliva samples include in the analysis, not the number of participants. 


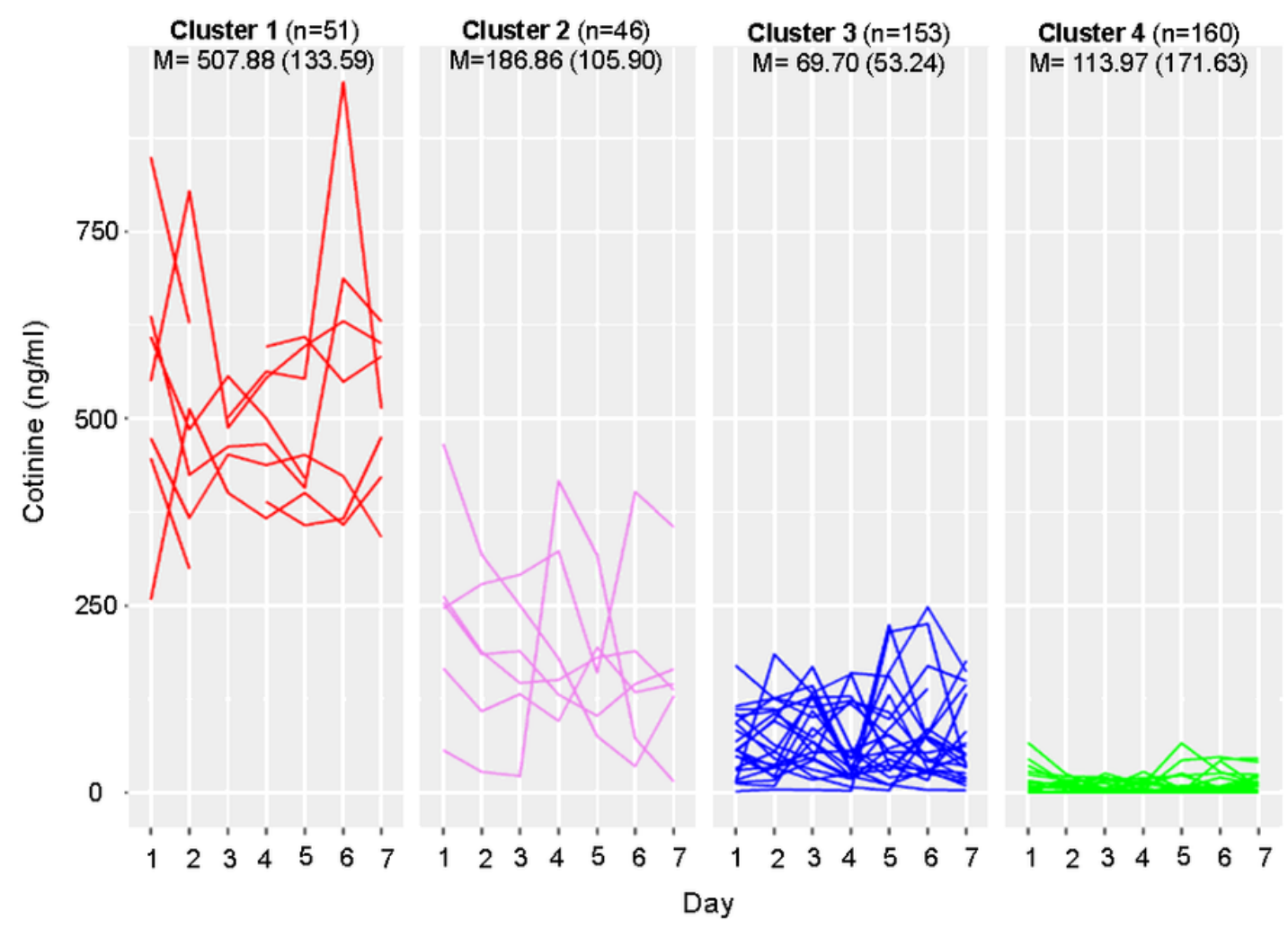

\section{Figure 1}

Results of the cluster analysis categorizing participants into groups based on similar mean levels of cotinine across 7 days of saliva collection. Cotinine was analyzed using ELISA. The sample size (n) in the figure is the number of saliva samples include in the analysis, not the number of participants. 


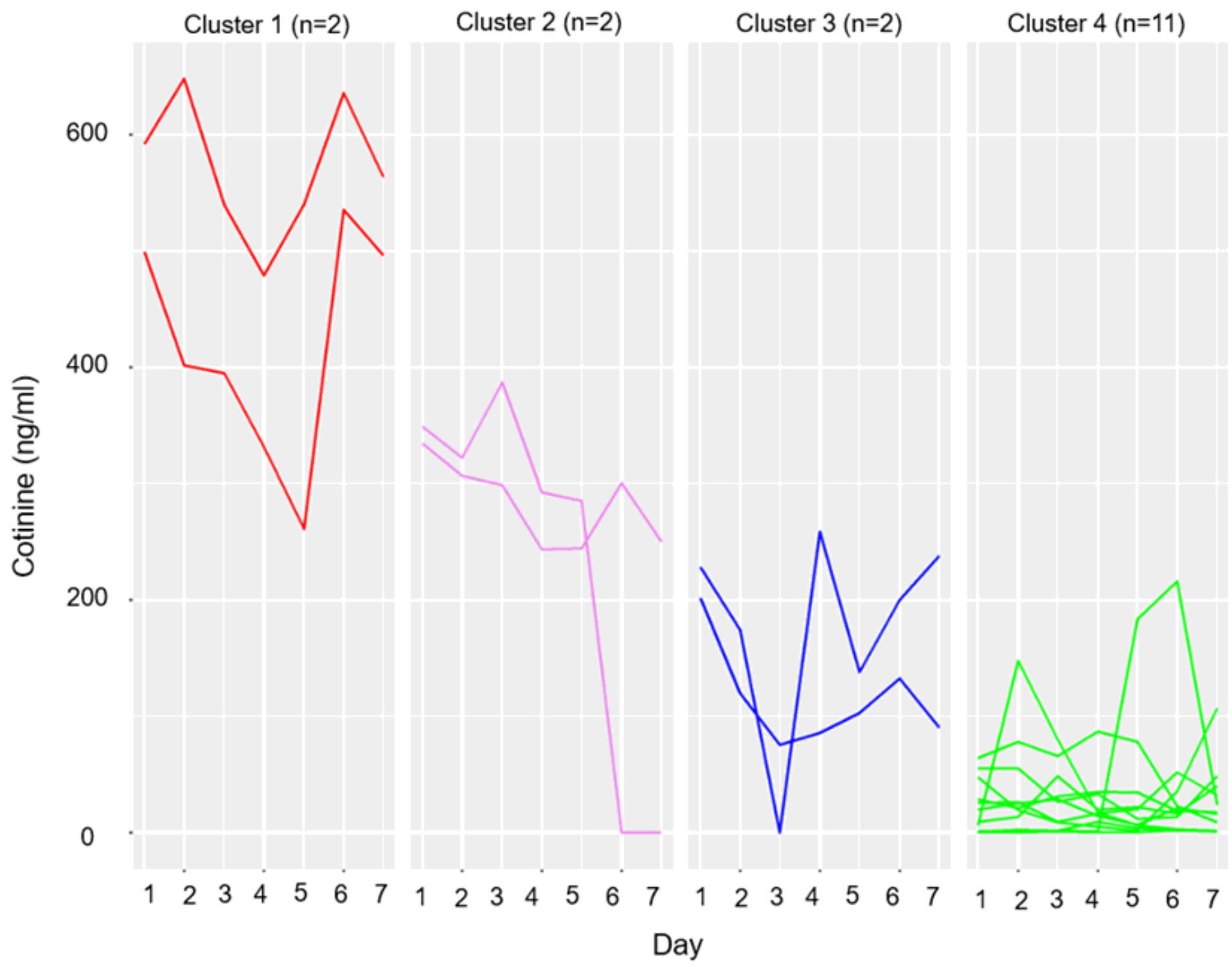

Figure 2

Results of the cluster analysis confirming the four-cluster model in a sub-sample of 17 participants whose cotinine values were derived using mass spectrometry analysis. 


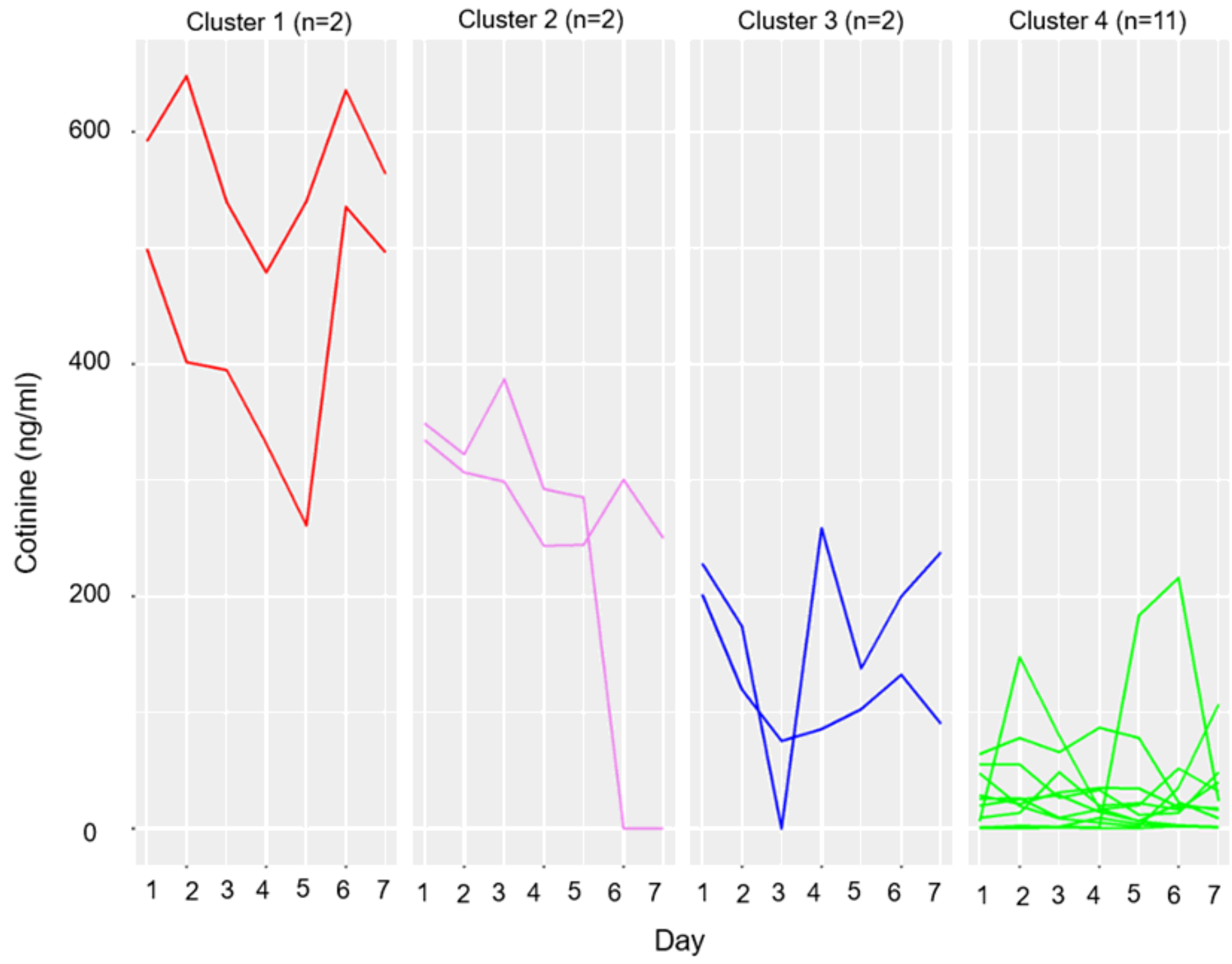

Figure 2

Results of the cluster analysis confirming the four-cluster model in a sub-sample of 17 participants whose cotinine values were derived using mass spectrometry analysis.

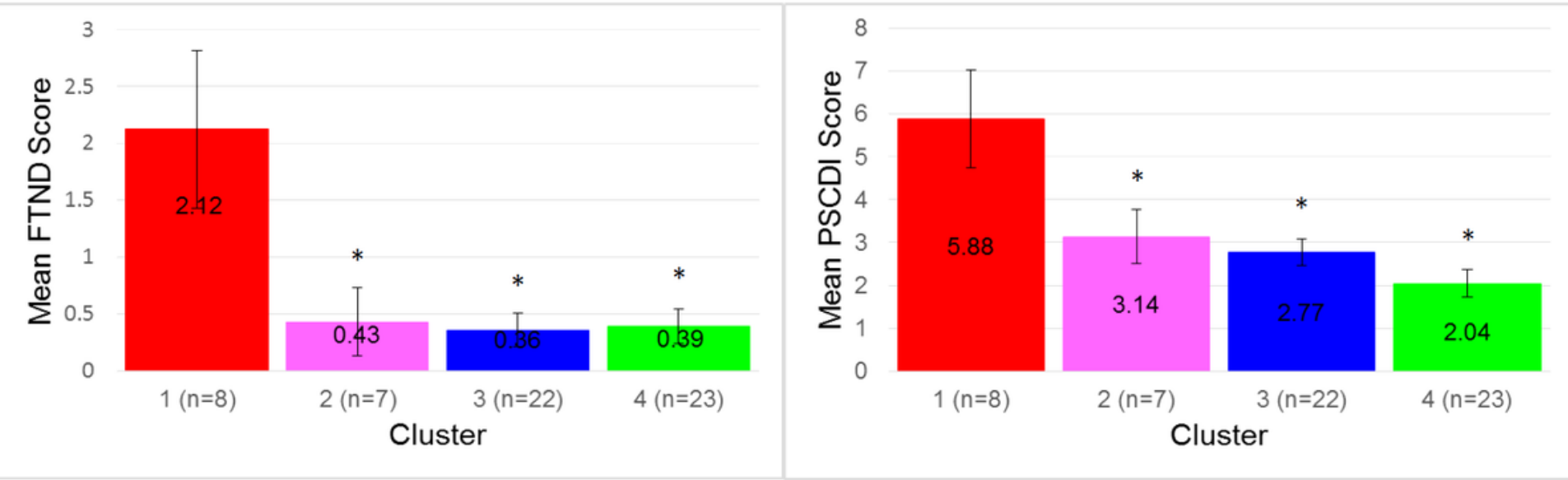




\section{Figure 3}

Bar graphs of dependence score means and standard errors on the Fagerström Test for Nicotine Dependence (FTND) and the Penn State Cigarette Dependence Index (PSCDI) across all 4 clusters. An asterisk indicates a significant difference from cluster 1 .

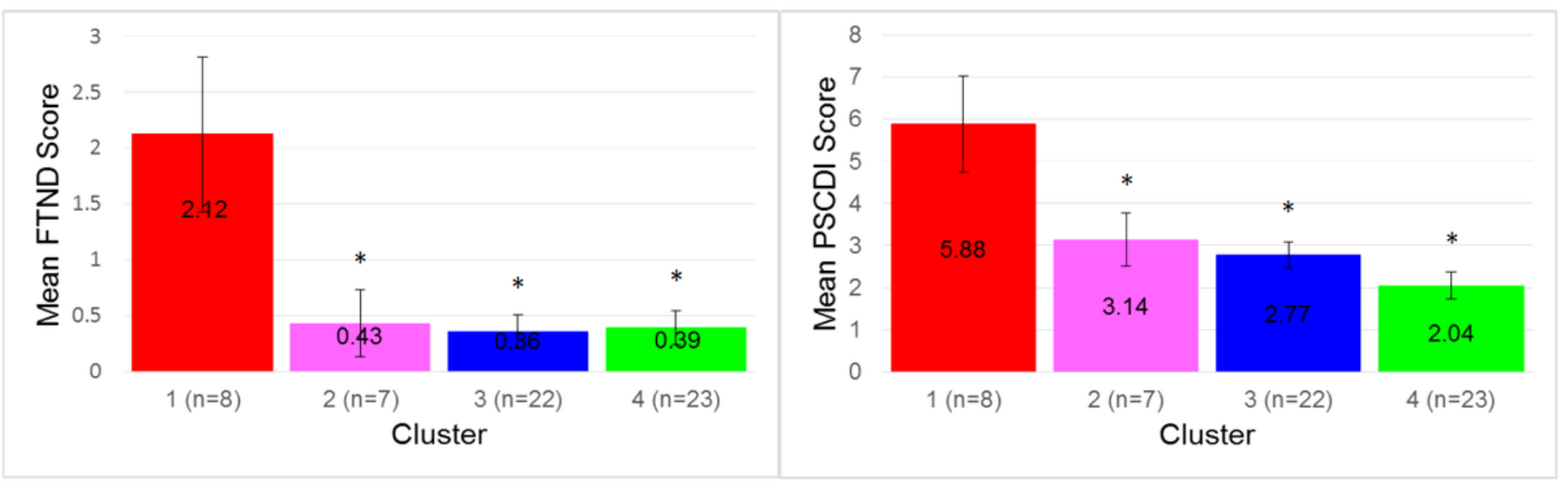

\section{Figure 3}

Bar graphs of dependence score means and standard errors on the Fagerström Test for Nicotine Dependence (FTND) and the Penn State Cigarette Dependence Index (PSCDI) across all 4 clusters. An asterisk indicates a significant difference from cluster 1 .
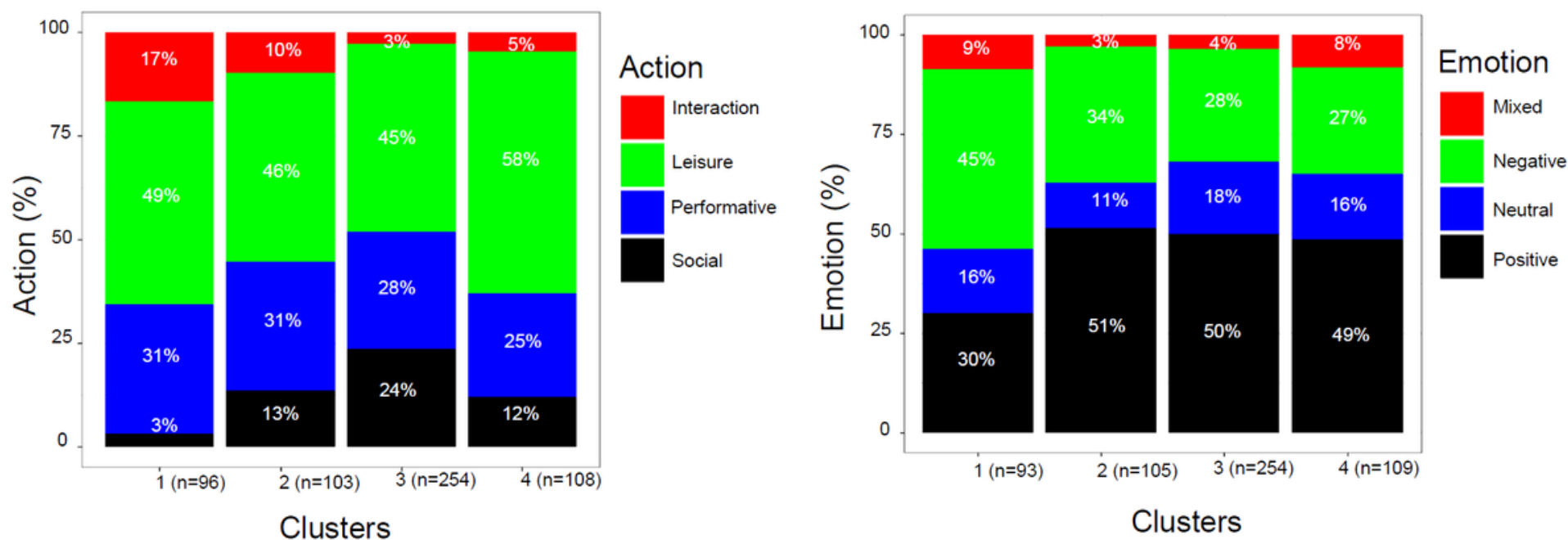

\section{Figure 4}

The proportion of actions and emotions recorded during smoking sessions in the 7-day at-home protocol for each cluster. 

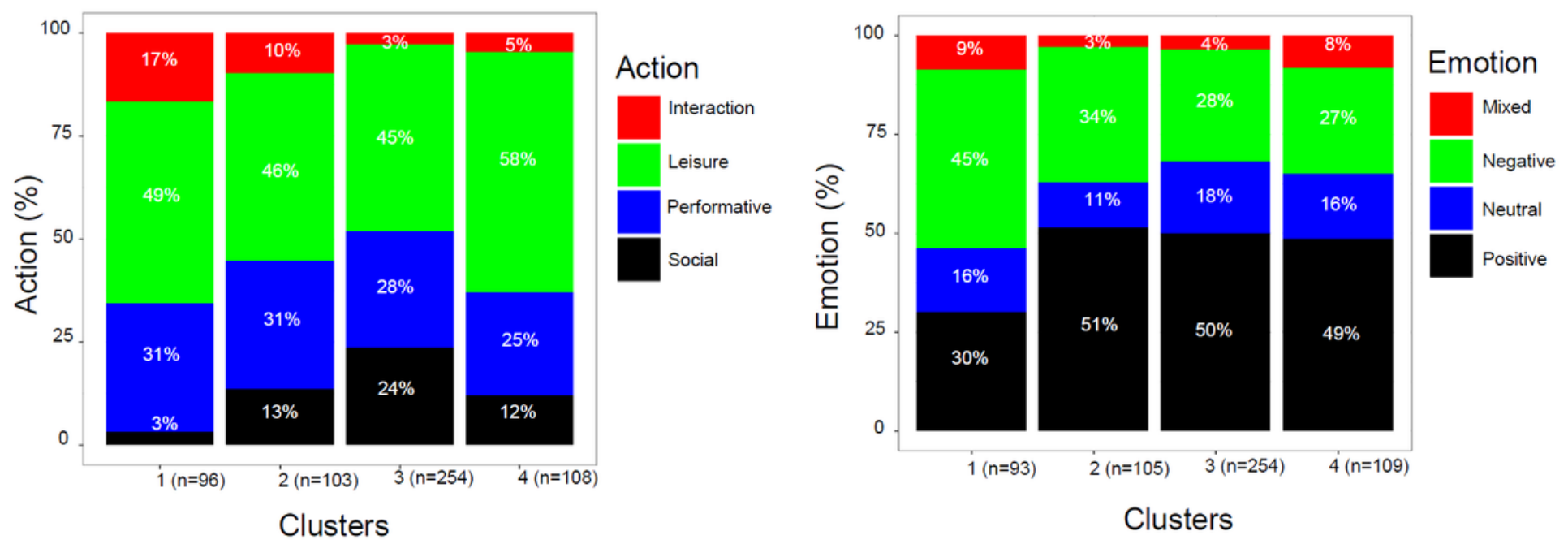

Figure 4

The proportion of actions and emotions recorded during smoking sessions in the 7-day at-home protocol for each cluster. 